\title{
As Novas Biotecnologias da Reprodução e a Subjetividade na Atualidade: caminhando entre a técnica e o humano
}

\section{New Reproduction Biotechnologies and Subjectivity Nowadays: walking between the technique and the human}

Artigo

Original

\section{Original}

Paper

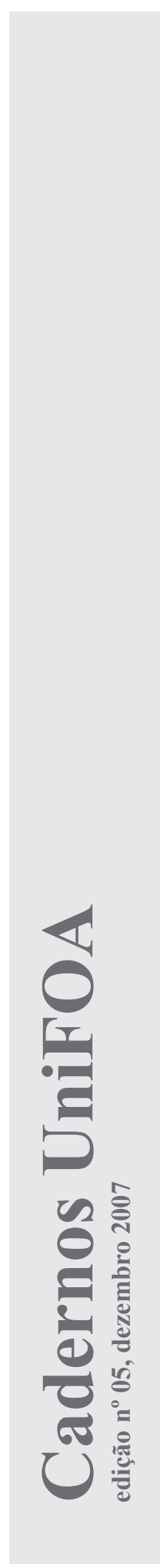

Júlio Cesar de Almeida Nobre ${ }^{1}$

Palavras-chaves:

Subjetividade

Biotecnologias

Redes

Híbridos
Key words:

Subjectivity

Biotechnologies

Nets

Hybrids

\section{Introdução}

Ao direcionarmos nosso olhar para a atualidade, podemos observar que muitas fronteiras que conferiam estabilidade, unidade, às nossas perspectivas parecem perder sua condição e capacidade ordenadora. Grande é a instabilidade e a vertigem no mundo atual e, intensas são as hibridações entre categorias - vistas, até então, como totalmente estáveis.
Uma importante e crucial vertigem, muito comum aos olhares atuais, é o que chamamos de artificialização do humano.

Diversas são as situações e práticas, hoje em dia, em que se encontra grande dificuldade de delimitação do exato ponto onde começa o artifício e termina a humanidade - e vice versa. Tal dificuldade parece se ampliar 
e se radicalizar bastante quando o assunto segue na direção das novas tecnologias - e mais especificamente aquelas voltadas para reprodução humana. Tais tecnologias, ao buscarem intensamente uma melhoria da vida humana, parecem insinuar, simultaneamente, um processo cada vez mais "artificializado" na própria produção desta mesma vida humana - trazendo à pauta diversas questões.

Diante de tal quadro, muitos são os autores que procuram alertar para alguns males e defender posições nativas de ordenamento como sujeito e humanidade. Em tais concepções, esses conceitos parecem ser entendidos como substância totalmente exterior ao artifício. Buscamos aqui uma sintonia diferente. O objetivo do presente trabalho, portanto, é a realização de uma reflexão que aponte para uma alternativa no modo como podemos pensar tal quadro de intensa mistura entre o humano e o artifício - quadro este radicalizado com o surgimento de novas tecnologias da reprodução.

\section{Subjetividade e Atualidade}

\subsection{A Atualidade e o Fim do Sonho da Unidade}

Muitos são os autores a caracterizar nossa atualidade como um momento bastante singular de transformação da subjetividade. Vivemos em um período de intensa turbulência na condição do sujeito moderno, período este comumente denominado como PósModernidade - apesar de não haver consenso em tais definições. A maioria dos autores, a abordar tal quadro, aponta como característica de nosso tempo, um esvaziamento das grandes narrativas, dos ordenamentos que se queriam totalizantes. A perda de referências se encontra na ordem do dia e aponta para a configuração de intensas vertigens. Perde-se aquilo que Dany-Robert Dufour (2005) aponta como o "em nome de", uma instância que nos serve de orientação. Desde o advento da condição moderna, seguimos em um processo de construção de um sujeito autônomo e livre, mas tal processo para Dufour, é extremamente problemático, como veremos. Em nosso percurso, uma pergunta de faz imperativa: o que se pode entender por um sujeito autônomo?
Segundo Dufour, para respondermos a tal pergunta, faz-se necessário, a priori, entendermos o que seria o assujeitamento. $\mathrm{O}$ sujeito é, em suas bases, submisso a alguma coisa. A existência do sujeito advém sempre de um Outro. Tal Outro é um princípio unificador que organiza/cria a realidade. Tal unidade é construída pela totalidade dos falantes e é a base da polis, da política.

(...) a política concerne ao que é comum a humanos que vivem juntos em um tempo e em um lugar determinados. A política remete, portanto, ao ser comum dos homens. Os conjuntos humanos não existem sem um princípio de unidade (Dufour, 2005, 30).

Vemos em Dufour a necessidade da existência de um princípio unificador a organizar os coletivos comuns. Tal princípio tem o estatuto de uma ficção, construção coletiva, política a envolver mitos, artes, discursos, etc. Essa ficção sustenta a possibilidade do fundamento, da inteireza nas bases de apoio para os discursos dos sujeitos.

No sentido de uma historicização do sujeito, Dufour sinaliza que a Modernidade correspondeu ao fim da unidade, da existência de um único grande Outro. Se nas sociedades mais tradicionais - ou pré-modernas - existia uma unidade hegemônica, um único grande Outro a ordenar o coletivo, nas sociedades modernas não mais.

Tornamo-nos modernos quando o mundo pára de ser fechado, voltado para si mesmo ou enclausurado em si mesmo por e para um grande sujeito, e quando ele se transforma (...) em um mundo aberto, múltiplo, até mesmo infinito (Dufour, 2005, 46-47)

O olhar sempre voltado para um paraíso que jamais será alcançado, constrói o percurso moderno de intensas conquistas e superações de sua própria condição moderna. As constantes construções modernas apontam para um modo de vida conquistador que instabiliza o passado e gera crises constantes. Diversos são os Outros produzidos a conviverem e trabalharem no assujeitamento. Transita-se entre esses, diversos Outros.

Voltando o olhar para a atualidade, Dufour encontra um aniquilamento da figura do Outro. Todas as ficções modernas continuam

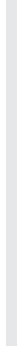


existindo, porém elas não detêm mais o poder de assujeitamento que sustentavam na condição moderna. Nenhum prestígio que possibilite a validação da ficção. Não tendo mais o "em nome de", ficamos "em nome de nós mesmos".

Nesse sentido, é idêntico dizer que a pósmodernidade é um regime sem outros ou (...) é repleta de semblantes de Outros, que imediatamente mostram o que são: tão cheios de presunção quanto às tripas (Dufour, 2005, 59).

Para Dufour, nos encontramos em um momento de ausência de referências, originado por uma ascese que buscava uma autonomia e liberdade humana. Buscamos autonomia e bem-aventurança; encontramos anomia e descaminhos. Qualquer princípio unificador transcendente, qualquer um "em nome de" que possibilite a construção de um assujeitamento parece ter se esvaziado. Vivemos em uma total imanência e nada mais desta escapa. Nenhum fora transcendente. Nenhum sonho de unidade.

O neoliberalismo (...) está se desfazendo de todas as trocas que subsistiam referidas a uma garantia absoluta ou metassocial das trocas. (...) Ora, doravante paramos de nos referir a qualquer valor transcendental para entrarmos nas trocas (Dufour, 2005, 12).

A condição humana começa a mudar em tal situação. Um sujeito preso a garantias transcendentais e em busca de sintonia com tais garantias abre espaço para um constante fluxo. Estar no fluxo parece ser o existir na atualidade. Para Dufour, a atualidade seria "psicotizante", configurando um sujeito totalmente aberto a toda e qualquer fluidez identitária. A impossibilidade de construção de um sujeito bem delineado, bem fundado, cede espaço a uma abertura constante às conexões. Parece que o trabalho em prol de uma liberdade humana teve como seu resultado a triste impossibilidade do fundamento do sujeito humano para Dufour.

\subsection{Atualidade e Turbulências na Condição do Humano}

Para Zygmunt Bauman (1998), em sintonia com Dufour, o sonho moderno de autonomia foi trabalhar sempre tendo em vista a bem-aventurança da imortalidade. Mas tal trabalho, segundo o sociólogo, teve como pressuposto o conhecimento de sua condição de mortal, finita; do contrário, tal sonho não teria um sentido de existir. Dessa forma, o olhar moderno se permeou pelo sempre constante risco envolto na sua condição de mortal, onde mortalidade e imortalidade são lados de uma mesma moeda e não existe uma sem a outra. $\mathrm{O}$ indivíduo, nessa Modernidade de risco, tem sua relação com a incerteza em muito mediada pelo conhecimento especializado. Acreditase na possibilidade de gestão dos riscos por intermédio deste conhecimento. A razão humana, dessa forma, possibilitaria um abrigo para o indivíduo contra tais riscos à vida.

Os humanos buscaram tal imortalidade de diversas formas ao longo da história. Em tempos pré-modernos, algumas personalidades visaram fixar seus feitos individuais na história, uma tão sonhada imortalidade individual. Grandes líderes, governantes e suas conquistas, bem como grandes poetas, pensadores e suas autorias marcavam-se na atemporalidade. Uma outra forma de imortalidade era alcançada ao participar de agrupamentos humanos, maiores que o próprio indivíduo, que continuariam a existir após sua morte física; essa, por sua vez, seria uma imortalidade coletiva. Desse modo, portanto, os humanos sobreviveriam à própria finitude corporal.

Com o advento da condição moderna, um sujeito racional e crítico é trazido a um patamar central. Toda e qualquer resistência à liberdade da vontade humana passa a ser entendida como obstáculo a ser superado. Adentra o humanismo e um sonho de liberdade e autonomia humanas - assim como nos apontou Dufour. A mortalidade do ser humano passa a ser um imperativo limitante e, portanto, algo abominável. Sendo assim, as práticas modernas tiveram muito do seu foco voltado para um afastamento desse horizonte fúnebre e inevitável. Buscou-se incessantemente afastar a ocorrência de todas as causas de mortalidade. A medicina tornouse prática privilegiada e ordenadora, nesse sentido. Vigiou-se a vida a todo o momento e se gerenciou incessantemente as probabilidades do morrer. Dessa forma, a possibilidade de 
imortalidade individual - que para os prémodernos era apenas uma possibilidade para as grandes e destacadas figuras e seus feitos - é disseminada. Em teoria, todos poderiam almejar a imortalidade individual via conhecimento médico especializado. "Com a tecnologia de transplante e substituição de órgãos, a ciência médica contemporânea adquiriu meios eficientes para prolongar a vida" (Bauman, 1998: 198).

Porém, para Bauman, a atualidade sugere despontar uma nova estratificação social, quando a imortalidade biológica parece estar a serviço de um processo cada vez mais radical de individualização. Apenas alguns terão acesso a essa "vida eterna" - até mesmo devido aos seus pesados custos. Sendo assim, a imortalidade parece configurar ser o aspecto central buscado na atualidade como fator individualizante. Ser imortal, saudável, "vivo" é ser meritoso. Nessa mesma direção, constata-se também um fechar de olhos para as realidades da mortalidade reveladas, segundo Bauman, em uma banalização da morte do outro, exibida sempre espetacularmente e de forma cotidiana na mídia, visando ofuscar sua própria visibilidade ao vulgarizá-la - um apagamento da morte daqueles que são próximos - vislumbrado nos funerais atuais mais escondidos, na reclusão cada vez maior de idosos e situações similares ${ }^{1}$.

Nesse ponto, parece haver uma grande sintonia entre o pensamento de Bauman, Rabinow (2002) e Ortega (2003). Rabinow afirma que estamos situados em pleno surgimento daquilo que ele chama de biossociabilidade, onde uma nova genética aponta para a uma constante modelação da vida que se espalha por todo o social. A natureza passa a ser produzida constantemente pela prática imanente. Biossociabilidade também pode ser entendida, segundo Ortega, como visando uma descrição e análise das

(...) novas formas de sociabilidade surgidas da interação do capital com as biotecnologias e a medicina. A biossociabilidade é uma forma de sociabilidade apolítica constituída por grupos de interesses privados não mais reunidos segundo critérios de agrupamento tradicional (...), mas segundo critérios de saúde, performances corporais, doenças específicas, longevidade, etc (Ortega, 2003, 63).

Assim como já nos apontava Bauman, o próprio envelhecimento, segundo Ortega, é agora patologizado. Velhice parece se configurar como uma doença a ser evitada e curada. Idosos são "trancados" e isolados em instituições de saúde. Enquanto isso, na mídia, os idosos apresentam características de jovialidade, bastante energia, "vida".

A partir da dimensão da biossociabilidade, Rabinow e Ortega trazem o foco da discussão para o tema do risco. Ao abordar tal questão, os autores sinalizam que na busca constante pela prevenção da saúde, humanos ordenam e gerenciam os riscos, isto é, vigiam - a todo o momento - a probabilidade de ocorrência de desvios do padrão. Ao concebermos - assim como Rabinow e Ortega - que a atual biossociabilidade se caracteriza por tais práticas, entendemos também que o mal, o erro, muitas vezes, poderá estar no nosso corpo, em nós mesmos. Passamos a tentar antever ocorrências que divergem do esperado. Vemos ações, sempre individuais, que se direcionam para objetivos de obtenção de uma forma física maximizada, longevidade e jovialidade. Podemos, também, vislumbrar uma engenharia genética a caminhar nessa mesma direção e a se antecipar e intervir em relação às possibilidades de acontecimentos fora dos padrões. Tal concepção de gestão de risco se coaduna, como já vimos, com a concepção de um sujeito racional e centrado. Tal sujeito poderia bem representar as situações a serem enfrentadas por ele e gerir seus riscos por intermédio de uma tecnociência a ele exterior.

Paula Sibilia (2006) parece complementar tais pensamentos, apontando para uma ascese que se instaura na atualidade, relacionada com o vencer no mercado das aparências, na busca pela eficiência e sucesso. Tal ascese - ou bioasceses - relaciona-se com a busca de um corpo perfeito, saudável. Essa perfeição envolve práticas como dietas, "malhações", vitaminas, cirurgias, botox, etc. Vemos um esforço desenfreado pelo

\footnotetext{
${ }^{1}$ Ao fecharmos os olhos para nossa mortalidade, Bauman alerta que fechamos os olhos para a própria especificidade humana. A consciência da morte era, segundo o autor, a mola propulsora de toda a grandeza construída pelos modernos em suas buscas pela imortalidade. Parece que sempre construímos transcendências, "belas" infinitudes em função de nossa condição imanente, finita. Bauman parece apontar para uma condição "esvaziada" atual.
} 
corpo "bom" e uma divisão bastante forte na atualidade entre os puros e os impuros: aqueles dotados de gorduras indesejadas. O olhar voltado para a pureza do saudável - o "vivo" - demoniza tais figuras fora do padrão e indica possibilidades de "cura". Cria-se um modelo ideal a partir do qual, aquele que não está no padrão passa a ser entendido como sendo "errado". Tais indivíduos, entendidos como portadores do "erro", passam a ser entendidos também como portadores de risco. Trazem a morte, a doença, enfim, o risco à ordem estabelecida, ao puro. Em uma atualidade onde o humano se quer livre, "só não é saudável quem não quer”. A gestão dos riscos está à disposição de quem assim o quiser: basta se utilizar da tecnologia disponível.

Tais práticas de gestão de riscos configuram práticas ascéticas que parecem tecer um processo de produção de subjetividade e corporalidade simultaneamente. Vemos práticas bioascéticas que vão da aplicação de botox a cirurgias plásticas - e caminhando na direção da engenharia genética - imbricadas com a subjetividade e constituindo o que Ortega denomina como bioidentidades.

Trata-se da formação de um sujeito que se autocontrola, autovigia e autogoverna. Uma característica fundamental dessa atividade é a autoperitagem. O eu que se perícia tem no corpo e no ato de se periciar a fonte básica de sua identidade (Ortega, 2003: 64).

A crença no sujeito racional capaz de gerir seus próprios riscos anda, em paralelo, aqui, com a concepção de que uma respectiva conseqüência desponta devido a uma ação bem delimitada e determinada - relação causa-efeito. $\mathrm{O}$ eu estaria sob controle da própria reflexão e o amanhã estaria, portanto, no controle daqueles que agem racionalmente e de forma precisa. Tal concepção, portanto, insinua uma dicotomia básica, uma relação dentro/fora entre tecnologia/conhecimento/ artifício e uma humanidade, em que o sujeito humano gere sua vida livremente e de forma autônoma - individualista - utilizando-se desses "maravilhosos seres artificiais" que lhe são exteriores.
A tecnologia digital parece ser um novo aliado na atual busca por uma purificação do corpo e de sua aparência ${ }^{2}$.

Pois esse modelo corporal fat-free (...) parece se aproximar, cada vez mais, de um ideal de pureza digital. Não é por acaso que programas de edição gráfica como o Photoshop desempenham um papel tão fundamental na construção das imagens publicitárias e midiáticas que expõem corpos belos (Sibilia, 2006, 8).

Todas as impurezas são retocadas em um ideal de perfeição, cuja imperfeição é associada ao corpo analógico. O orgânico precisa ser purificado. Eé isso que encontramos em nosso cotidiano. Buscas incessantes por recursos que nos tornem "melhores" e "retocados". Mas quando contrastamos imagens "originais" com as já alteradas pelo computador, eis que surge um impacto...

(...) o primeiro efeito da aparição da fotografia originaléum estranhamento e atécertaimpressão de monstruosidade, em contraste com a versão límpida e pura que resultou da aplicação dos truques digitais. Em seguida, porém, o olhar detecta a artificialidade da imagem retocada e toda a sensação de estranheza logo se esvai. $\mathrm{Ou}$, inclusive, chega a se deslocar para a versão digitalizada (Sibilia, 2006, 9).

Tal impacto parece revelar como um olhar dicotômico entre humanidade e artifício parece problemático na atualidade. No trecho acima citado vemos, em um primeiro momento, um olhar permeado pela estranheza entre diante de dois humanos muito diferentes, mas entendidos como a mesma pessoa: um é "feio e impuro" e o outro "bonito e perfeito". Tal vertigem parece também se situar nas fronteiras entre um humano original e um artifício. A sensação de estranheza sugere ir da imperfeição analógica - que parece tornar imperativa a pergunta "como pode isso?" - a uma perfeição construída apenas no campo digital - que parece, por fim, colocar tudo no seu devido lugar como sendo um total artifício. Mas qual é o lugar devido? Uma irrealidade digitalizada e aperfeiçoada ou

${ }^{2}$ Ortega acredita que tal quadro aponta para um esvaziamento da política na medida em que falta nestas a preocupação com o bem comum e com os outros. A preocupação com o próprio corpo, portanto, estaria criando uma falta de preocupação com o mundo 
um humano analógico e impuro. Parece que tal pergunta tem, cada vez mais, encontrado a resposta em um humano incansável em sua busca pela pureza proporcionada pela técnica, visto que tal modelo digital extrapola as telas dos computadores e permeia as subjetividades e os corpos. $\mathrm{O}$ digital gradualmente se mistura ao "real".

(...) Em 1999, a agência de modelos Elite lançou a primeira integrante de uma equipe de modelos digitais, versões em bits dos tipos femininos mais valorizados no mercado das aparências. (...) Ecoando esses fenômenos, a revista Playboy resolveu publicar uma série de ensaios eróticos com imagens de divas virtuais (...) e a TV Globo também acabou criando a sua própria bela digital para apresentar algumas matérias do programa Fantástico (Sibilia, 2006, 11)

Por outro lado, os atuais concursos de beleza se deparam com candidatas "freqüentadoras assíduas" das clínicas de renomados - nem sempre-cirurgiões plásticos e felizes entusiastas do botox, do silicone, etc. As controvérsias são imediatas: tais candidatas merecem ou não o prêmio? Que tipo de beleza é aquela? Beleza humana ou artificial?

\section{As Novas Biotecnologias da Reprodução e a Artificialização da Vida Humana}

As novas biotecnologias parecem apontar para um novo e mais radical estágio na busca por um corpo são. Novas tecnologias prometem, muitas vezes, em escala molecular, uma manipulação intensa do humano. Tais manipulações atuam em um campo - o do início da vida - que, segundo Kottow (2005) é o tema que, junto com a morte, marca mais presença na história do pensamento humano. Tecnologia, como apoio à vida humana, parece não assustar e ser aceita mais calmamente. Mas quando o assunto resvala no campo da reprodução in vitro - começam as controvérsias bioéticas e as denúncias de excesso de artificialidade na dimensão natural do início da vida humana.

Aquilo que entendemos por natureza humana - ordenamento de solidez inquestionável até então - parece se artificializar cada vez mais e gerar medo pelas implicações de tais procedimentos radicais. Nas tecnologias da reprodução, tais processos ficam bastante explicitados quando

(...) os processos de fecundação e reprodução artificializaram-se a tal ponto que é possível iniciar a vida humana em laboratório, modificar sua composição genética, selecionar o produto obtido e dar início a seu desenvolvimento, para depois entregar sua evolução e maturação a um útero humano, geneticamente relacionado ou não com o embrião" (Kottow, 2005, 21-22)

Em seu livro intitulado $\mathrm{O}$ Ovo Transparente, Jacques Testart (1995), líder da primeira equipe francesa de pesquisadores que conseguiu alcançar êxito na concepção de um bebê de proveta, já assinalava tal dimensão do artifício a se misturar com a reprodução humana; sendo esta, até então, percebida como algo natural. Testart, ao explanar sobre a felicidade dos pais diante do bebê fecundado in vitro, evidencia tal hibridação ao apontar que estes

(...) no final das provações de um percurso terapêutico impotente, descobriram na rotundidade de um ventre que eles se tornariam três. E que esse terceiro já não é a coisa de especialistas: livre de uma odisséia em que se misturavam seringas, hormônios, bisturis, tubos e líquidos artificiais, ele é apenas seu filho (Testart, 1995, 21).

Podemos perceber que o amor procriador dos genitores, além de se misturar com artefatos tecnológicos, parece começar a não necessitar mais do contato físico direto. Vemos também, em Testart, toda uma cadeia de artefatos que parecem redesenhar uma reprodução natural.

Primeiro, o receptáculo que recolhe o sêmen, cilindro da largura do polegar e do comprimento da mão, cuja antecâmara, de tamanho considerável, é orlada por uma franja vulvar. O cálice para a oferenda viril é um negativo fálico ou uma moldagem vaginal? Vem depois o tubo no qual se casam os gametas. O tubo é frágil, longo e reto; a língua inglesa (...) utiliza a mesma palavra (...) para designar a trompa uterina e a proveta. O tubo fica num recinto quente, ventre que, aliás, abriga os bebês prematuros. Quando se conclui a epopéia das células delegadas 
à procriação, as largas mãos do especulo distendem a vagina e o ovo é empurrado para a matriz, graças ao fino cateter. Este imita o longo meato do falo enrijecido; o músculo delega à seringa sua função ejaculatória (Testart, 1995, 22-23).

Tal quadro da fecundação in vitro e transferência de embrião parece apontar para possibilidades demasiadamente claras de escolhas deliberadas. Padrões específicos de crianças poderão ser optados. A concepção estaria às claras, sendo o humano passível de ser biologicamente projetado. O início e concepção da vida passariam a ser passíveis de manipulação e, portanto, artificialização.

Tais questionamentos ganham especial potencial de controvérsia no tema da "barriga de aluguel ${ }^{3}$ ". O material biológico implantado no útero receptor tem que estatuto? Ser humano ou um projeto? Filho ou estranho? Tais ambivalências desenham um cenário turbulento que parece trazer vertigens diante de fundamentos que há muito nos trazem tranqüilo assentamento.

Neste quadro atual, o campo das novas biotecnologias da reprodução humana parece ser atravessado por dilemas diversos e permeado por intensas controvérsias. Tais controvérsias parecem apresentar uma atualidade bastante temerosa dos poderes da técnica, do artifício, muitas vezes defendendo um sujeito que deve ser preservado em sua condição de humanidade.

\section{Considerações Finais: caminhando entre o artifício e o humano}

A experiência do risco parece se encontrar na pauta do dia. Tal risco pode ser considerado como uma característica própria de nossa atualidade - um estágio em que nos confrontamos com nossa própria criação, com nossos próprios limites. Os humanos, por intermédio da tecnologia, ao buscarem a melhoria da qualidade de vida, assumem uma condição ambivalente na medida em que geram, simultaneamente, novos riscos e novas condições - como no caso das biotecnologias da reprodução que geram tantas questões bioéticas. Esse entendimento tem construído, constantemente, uma subjetividade que continua operando através da gestão de riscos ao corpo e a saúde e com a crença em um sujeito crítico, unificado e racional. Como já nos dizia Rabinow, Ortega e Sibilia, constróise um campo de probabilidades de ocorrência dos riscos, a tal ponto que passa a configurar um campo virtual de gestão da existência, em que estatísticas, previsões, modelos e padrões de beleza convivem com nosso presente, orientando nossos movimentos. Mas a ironia é que a gestão dos riscos por intermédio das tecnologias, na busca de minimizar instabilidades, as gera simultaneamente. Quanto maior a busca pela pureza; renovados e ampliados são as instabilidades e os riscos - e tecnologia, aqui, é vetor de turbulência.

Tal subjetividade, que parece estar sendo tecida na atualidade, parece ser bioidentidade que se constitui na justa medida dos cuidados com seus corpos (Ortega, 2003). Determinados padrões subjetivos como força de vontade, responsabilidade, produtividade acabam por se agenciarem com o modo como se cuida do corpo - corpo este que parece não ser mais uma instância radicalmente separada da subjetividade.

$\mathrm{Na}$ nossa cultura somática, aparência virou essência (...). Hoje sou o que aparento e estou, portanto exposto ao olhar do outro (...) preciso de seu olhar, de ser percebido, senão não existo (Ortega, 2003, 69).

Como podemos ver, as práticas de bioascese tem um cunho individualista que traduzem uma preocupação com o "eu mesmo", o indivíduo - traduzido por sua dimensão corporal. Práticas como as tatuagens, piercings, body building e body modifications - e até mesmo as clonagens - são indicativos, segundo Ortega, de uma busca por personalização - e conseqüentemente uma constante produção do corpo/eu. Sibilia aponta que tais processos instáveis, na atualidade, indicam uma crucial mudança nos modos de intervenção tecnocientífica nos corpos. Se anteriormente, os esforços técnicos eram no sentido da melhora, do aperfeiçoamento, agora não mais. Vemos esforços, no sentido da criação e ultrapassagem ; e tal ultrapassagem, quando o assunto se focaliza nas biotecnologias da reprodução, gera

${ }^{3}$ Quando se alcança uma fecundação in vitro e se implanta o zigoto em um útero alugado ou emprestado 
intensas questões bioéticas. Nesse ponto, parece haver uma grande sintonia entre o pensamento de Sibilia e Laymert Garcia dos Santos (2003) quando se referem ao projeto "The Visible Human". Tal projeto diz respeito à fabricação de um humano plenamente visível lançado na internet e que tinha por objetivo possibilitar uma total visibilidade deste diante do olhar clínico. Catherine Waldby acrescenta, porém, que

(...) para transformar seus corpos em dados digitais foi preciso todo um procedimento que anulou literalmente a sua massa (...) cadáveres transfiguram-se numa série de imagens planas acessadas uma a uma para visualização, mas também manipuladas de modo ilimitado (in Garcia dos Santos, 2003, 266).

Saímos, portanto, do quadro das representações e entramos no campo das operações. Vemos a manipulação de um humano transformado em matéria prima. $\mathrm{O}$ corpo passa a ser um recurso a ser utilizado. Estamos diante de uma concepção do ser humano como orgânico e como técnica concomitantemente. Podemos encontrar nos ciborgues (Haraway, 2000) uma metáfora para tal situação. Esses seres que povoam amplamente os livros e filmes de ficção científica conseguem misturar tecnologia e humanidade em sua própria existência e indicam a impossibilidade de uma pureza humana ou inumana. Ele é híbrido de humano e técnica.

O humano, ao caminhar avidamente no sentido de uma purificação de sua condição, se depara com uma intensa hibridação. Tal hibridação parece apontar para um processo de produção sempre constante em que humanidade e artifício de reinventam a todo o momento. Pensamos que o modelo das redes sociotécnicas de Bruno Latour (2000) pode nos ajudar a realizar um maior aprofundamento nesta atualidade sinuosa. Redes são amarrações de diversos elementos/nós - que, por sua vez, são também mais amarrações. Vemos, portanto, um emaranhado de redes que fragmentam qualquer solidez em micropoderes, em conexões ou desconexões. Tal emaranhado nos possibilita pensar não mais em termos de unidade, de sujeito, mas a partir de um dinamismo processual e sempre constante de mediações.
A circulação nas tramas da rede se dá por meio de hibridações e, neste processo, a realidade vai sendo construída por tais potências criativas. Os coletivos não podem ser entendidos a partir de centros a priori. Dessa forma, a busca por uma unidade, pela pureza acaba por renovar, criar novos problemas e realizar uma abertura de portas que aponta para uma realidade sempre bifurcada. Purificar é misturar. Jamais fomos modernos (Latour, 1994). As purificações deslocam os ordenamentos e os híbridos entram em cena como potência de criação e imprevisibilidade, inerente aos agenciamentos proporcionados pelas próprias purificações.

Partindo de tal perspectiva, não podemos nos sintonizar com concepções nativas de um pensamento centrado no sujeito racional. O modelo de gestão de riscos parece pressupor uma unidade que não se sustenta quando a existência é pensada como rede. Nessa medida, aquilo que entendemos por sujeito/humanidade mescla-se com todo um conjunto de práticas interconectadas, fervilhantes, onde a concepção nativa do risco deixa de fazer sentido. Não podemos falar em risco quando tudo é instável. Quando tudo é impuro, como enxergar a partir de purezas?

A concepção de redes parece retirar o foco do sujeito fundado. O que existe são mediações e constante redefinição. Nenhuma garantia. Tais redefinições sempre tecem novas geografias e novos controles. Novas coerções exercem pressão sobre velhas coerções e as deslocam, descentram. É a partir dessa veloz mutabilidade que pensamos ser mais fértil o entendimento de artifício e humanidade como imbricadas. Tanto sujeitos humanos como tecnologias se reinventam mutuamente. A produção emrede aponta para o transbordamento que delineia novos ordenamentos na justa proporção de seus movimentos. A produção de um coletivo vai se dando por intermédio desses fluxos que se reapropriam da existência na construção do novo.

Não reivindicamos aqui, portanto, um sujeito e um fundamento que constitua sua inteireza. Um humano detentor do poder de conhecimento e utilização de um objeto técnico diante de uma situação passivamente colocada a sua frente. Não. Artifício e humanidade, um constante descentramento, é aqui nossa proposta. 


\section{Referências}

BAUMAN, Z. O Mal Estar da Pós

Modernidade. Rio de Janeiro: editora Zahar, 1998.

\section{DUFOUR, D. AArte de Reduzir as Cabeças:} sobre a nova servidão na sociedade ultraliberal. Rio de Janeiro: Companhia de Freud, 2005.

GARCIA dos SANTOS, L. Politizar as Novas Tecnologias (impacto sociotécnico da informação). São Paulo: Editora 34, 2003.

HARAWAY, D. Manifesto ciborgue: ciência, tecnologia e feminismo-socialista no final do século XX. In: Silva, T. T. da (Org.). Antropologia do Ciborgue - as vertigens do pós-humano. Belo Horizonte: Autêntica, pp. 37-129, 2000.

KOTTOW, M. A Bioética do Início da Vida. In Schramm, F. R. \& Braz, M. (Org.). Bioética e Saúde: Novos tempos para mulheres e crianças? Ed. FIOCRUZ, 2005.
LATOUR, B. Jamais fomos modernos. São Paulo: Editora 34, 1994.

Ciência em ação: como seguir cientistas e engenheiros sociedade afora. São Paulo: Editora UNESP, 2000.

ORTEGA, F. Praticas de Ascese Corporal e Constituição de Bioidentidades. In: Cadernos de Saúde Coletiva. Rio de Janeiro, 11 (1): 59$77,2003$.

RABINOW, P. Antropologia da Razão. Rio de Janeiro: Relume Dumará, 2002.

SIBILIA, P. O bisturi de software: Como fazer um corpo belo virtualizando a carne impura? In: ARAÚJO, Denize. (Org.). Imagem (IR) Realidad. 1 ed. Porto Alegre: Sulina, v. 1, p. 271-289, 2006.

TESTART, J. O Ovo Transparente. São Paulo: Editora da Universidade de São Paulo, 1995.

Informações bibliográficas:

Conforme a NBR 6023:2002 da Associação Brasileira de Normas Técnicas (ABNT), este texto científico publicado em periódico eletrônico deve ser citado da seguinte forma:

NOBRE, J. C. A.. As Novas Biotecnologias da Reprodução e a Subjetividade na Atualidade: caminhando entre a técnica e o humano. Cadernos UniFOA, Volta Redonda, ano 2, nº 5, dez. 2007. Disponível em: $<$ http://www.unifoa.edu.br/pesquisa/caderno/edicao/05/42.pdf $>$ 